\title{
LA MUERTE EN LA MEDICINA INDÍGENA
}

Liliana Támara Patiño, $M D$ *

\section{Contexto personal}

Abordar el tema de la muerte, el proceso de morir y el duelo, requirió en mi experiencia personal un largo recorrido de pensamiento, cerca de 13 años de experiencias como estudiante de medicina de la Universidad del Rosario, primero como médica en entrenamiento en cuidados paliativos, y luego en ejercicio en la Fundación Omega y en la unidad de oncología del Hospital Infantil Lorencita Villegas de Santos, como experta en bioética de la Universidad El Bosque y ahora como colaboradora en el ejercicio de la medicina tradicional indígena por parte del Taita Orlando Gaitán; pero en especial el sentimiento como ser humano, como paciente oncológica de la medicina no indígena y de la medicina indígena. ${ }^{1}$

\section{EI ejercicio médico hoy, la enfermedad y la muerte}

De esta manera, debo situarme en el deseo que me movió a convertirme en médico, yo quería ayudar a las personas a aliviar su dolor y su sufrimiento y al parecer, el mejor camino dentro de nuestra sociedad para lograrlo era la carrera de medicina. Allí además de ayudar, el principal objetivo era aprender a curar las enfermedades y a luchar contra la muerte. Para ello se apelaba a enseñar todas las herramientas de

\footnotetext{
Médica de la Universidad del Rosario. Fundación Carare. Bioeticista. Conferencia dictada en el Hospital de San José, durante las jornadas sobre Medicina en el arte prehispánico colombo-ecuatoriano. Septiembre de 2004.

I A lo largo del texto me referiré a la medicina tradicional indígena, como medicina indígena y a las otras medicinas incluida la académica de legado galénico, como medicina no indígena. Estas referencias provienen de un largo proceso de trabajo a raíz de investigaciones realizadas para el Ministerio de Salud de Colombia alrededor de la problemática de las ETS y elVIH-SIDA en algunas comunidades indígenas.
}

que la medicina dispone, el arte, la ciencia y la magia para curar, dentro de un currículo visible catedrático, transmisible a través de los textos que recopilan este conocimiento, pero también a través de un currículo no visible a partir de la transmisión oral y de la práctica que diariamente los profesores y los pacientes enseñaban en cada experiencia.

Sin embargo a lo largo de este camino, el arte y la magia se fueron desdibujando para ser reemplazadas en algunos casos, casi que solo por la ciencia. Y la enseñanza que se vivió mostró una relación médico paciente mediatizada, distante, instrumentalizada, fría, ausente, sin contacto y sin recursos, una relación que enfermaba más que curar, que dolía más que aliviar y que mataba las ilusiones de los pacientes y sus familias que llegaban a buscar otro tipo de encuentro.

En este contexto la enseñanza mostraba a la muerte como una enemiga, que nos deja desolados, que no sabemos cómo manejar, cómo enfrentarla, cómo comunicar su proximidad o su llegada. Y el después de la muerte se le deja a los sacerdotes, a los pastores, a los familiares y no se tiene en cuenta dentro de la enseñanza médica.

Ante este vacío, se difunde a lo largo del mundo a finales del siglo XX el cuidado paliativo, a partir del movimiento de los hospices en cabeza de Cicely Saunders en Inglaterra, como la mejor forma de afrontar la muerte, el morir y el duelo desde una manera más humana, para los pacientes que sufren de alguna enfermedad; opto por este camino. En el cuidado paliativo se le provee al paciente y a su familia, por lo regular en su propio entorno, el alivio de síntomas,el apoyo emocional, social y la asistencia religiosa. Este movimiento ha contado con menor o mayor apoyo en cada 
país de acuerdo con sus propias condiciones sociales $\mathrm{y}$ es innegable que ha brindado innumerable serie de herramientas a los médicos, enfermeras, psicólogos, trabajadores sociales y todos aquellos que se enfrentan a la muerte en los hospitales, centros de salud o en las casas de los pacientes. Incluso ha prestado elementos a la tanatología para enfrentar la muerte violenta a nivel individual y social.

Sin embargo, pese a todos estos aportes, la muerte sigue siendo difícil de enfrentar en nuestras sociedades, a pesar de su connaturalidad a la condición humana, es por ello que a continuación tomaré algunos elementos que la medicina indígena puede aportar para su manejo.

\section{La medicina indígena}

Para empezar, es importante recalcar que la esencia del mundo indígena es una permanente opción por la vida y de allí parte el concepto de salud, como armonía, un juego funcional perfecto de encuentro consigo mismo, con el entorno y con $\operatorname{Dios}^{2}$ y en contraposición se encuentra la enfermedad, como ese desequilibrio que no permite la armonía y que se representa a través de manifestaciones diversas de orden físico o no físico.

Cuando en un proceso de enfermedad o fuera de él, aparece la muerte dentro del mundo indígena, se entiende que la misma solo es cambiar. Y este cambiar tiene dos puntos de partida, uno es el cambio de estado físico, en donde los elementos de la naturaleza y en especial para el mundo indígena la tierra adquiere un papel preponderante, pues ella se encarga de transformar las partículas de materia, de las cuales ha estado compuesto el cuerpo, en otras formas de vida. Recupera todos los compuestos materiales del mismo, los procesa y los convierte en materia para la continua generación.

2 Ver los conceptos de salud y enfermedades de las referencias, especialmente los trabajados en las investigaciones realizadas para el Ministerio de Salud.
De esta manera, el mundo indígena cambia el concepto sobre lo que significa la vida y la relación hombre-naturaleza, estrechando el vínculo de la misma esencia material del hombre y de todos los seres vivos, con la tierra como madre, permanente productora de elementos formes para la vida. Es en este espacio donde se puede encontrar al amor, a la maternidad, al crecimiento, al aprendizaje y a la esencia de Dios en la vida.

El otro cambio es el espiritual, donde se muere para volver a vibrar al mismo ritmo del universo, donde se realiza un reencuentro con el Creador y con la armonía de toda la obra creada. Donde el espíritu de cada ser vuelve a su origen. Y este cambio, se puede sentir, percibir a través de diferentes rituales indígenas, incluso cuando aún no es el momento del morir físico final como humano.

En esta visión del mundo indígena sobre la muerte, la medicina indígena y especialmente el médico tradicional indígena, evidencian su papel de manera clara, puesto que el médico indígena o chamán es el garante de la vida. Es un transformador de la vida y de la muerte, de sus formas y manifestaciones, hacia una permanencia de la vida. De esta manera, toma elementos naturales, plantas y animales para permitir la continua recreación de la vida, para todos los seres vivos, incluidos los humanos.

Así, cuando ya se ha instaurado un proceso de enfermedad, el chamán puede preparar remedios a base de plantas, animales y otros elementos de la naturaleza con el fin de curar estas enfermedades, así como de aliviar el dolor y el sufrimiento. Cuando el proceso de enfermedad ya no es reversible y no se puede lograr una curación del cuerpo que pueda permitir continuar con esa forma de vida que lleva, el chamán orienta su práctica en la persona hacia el alivio del dolor y el sufrimiento, además de un proceso de limpieza espiritual que le permita al espíritu de ese individuo lograr hacer ese cambio de estado espiritual y reencontrarse con su principio creador. Con la familia y la comunidad el chamán hace un proceso de 


\section{HISTORIA DE LA MEDICINA}

preparación físico, emocional, social y espiritual, que les permita a los seres queridos, allegados y demás hacer un acompañamiento saludable para todos en un ámbito de verdad, amor, perdón y reconciliación, y de esta manera asegurar que la vida continúe para los que quedan y para el que se va. Estos procesos los hace a través de remedios preparados, rituales de limpieza, la palabra y su acompañamiento físico y espiritual.

El chamán también se encarga de prevenir que aparezcan situaciones individuales o colectivas que conlleven a la muerte, bien sea por enfermedades o por otras situaciones generadas por las relaciones que se instauran con otros grupos poblacionales, con otros pensamientos y prácticas e incluso con el entorno ambiental que los rodea. Esto lo hace a través de recomendaciones de buen vivir, enseñanza de su conocimiento y sabiduría sobre las leyes de la vida, alianzas y pagamentos a los espíritus de los elementos naturales (agua, tierra, fuego, aire), las plantas y los animales de tal forma que se pueda vivir y convivir felizmente. Pero, si a pesar de las recomendaciones y avisos que el chamán ha hecho, por enfrentamientos, desobediencia o mal manejo, una persona muere "accidental" o violentamente, el chamán continúa su labor de reconciliación de ese espíritu con los seres queridos, allegados, los demás miembros de la comunidad e incluso de fuera de ello. A través de ceremonias rituales puede ayudar al que muere a seguir su camino espiritual, dejando solucionadas en la medida de lo posible sus asuntos con su familia, incluso logrando comunicación entre los dos mundos para aliviar la pena y la incertidumbre que se podrían presentar en estos casos. Pero también fortaleciendo las barreras de separación entre el mundo de los vivos y el de los muertos, para evitar que una comunicación abierta entre ambos conlleve a una sucesión de muertes entre los miembros de una familia o de la comunidad.

Para finalizar, es importante pronunciarse sobre el papel del chamán como orientador del progreso de una persona, de una familia o de toda una comunidad.
Pues, como garante de la vida, debe entenderse con todos los asuntos que permitan que ésta siga floreciendo a través de todas sus manifestaciones, especialmente de la humana.

\section{Reflexiones finales}

Este recorrido que he hecho, a lo largo de la medicina no indígena y de la medicina indígena y que empezó con preguntas básicas acerca de la muerte, del dolor y del sufrimiento como hechos evidentes en la realidad humana, me ha llenado de elementos para sentir la vida con mayor intensidad, con más serenidad y tranquilidad y con mucho más bienestar.

La medicina indígena nos proporciona elementos reales, tangibles, visibles y evidentes, que por el hecho de no tener una explicación racional, no significa que no existan y que no permitan que la vida transcurra de una mejor manera, más feliz y más trascendente.

Este camino de conocer sobre la muerte, sobre la enfermedad, sobre el dolor y el sufrimiento, es solo una vía para encontrar este sentido de vida. Y es mi deber informar a otras personas, sobre los recorridos que hemos hecho, de tal forma que puedan tener más herramientas para continuar en este progreso hacia un mejor vivir para todos.

\section{REFERENCIAS}

1. Gaitán $\mathrm{O}$, Aldana D, Trujillo J, Támara L. Investigación cualitativa sobre los conceptos de salud y enfermedad alrededor de las ETS, el VIH y el SIDA en las comunidades indígenas Inga, Siona, Kamentsá y Kofán del departamento del Putumayo y la comunidad Zenú de los departamentos de Córdoba y Sucre. Ministerio de Salud. 1990.

2. Gaitán O, Trujillo J, Támara L. Formulación de los Planes de Promoción de la salud, prevención y atención de las ETS, el VIH y el SIDA para las comunidades Siona del departamento del Putumayo y Zenú de los departamentos de Córdoba y Sucre. Ministerio de Salud. 1990.

3. Bejarano P, Fonnegra I, et al. Fundamentos del Cuidado Paliativo. Bogotá; Fundación Omega,1996. 